\title{
Using of alternative fillers based on the waste and its effect on the rubber properties
}

\author{
Mariana Pajtášová, ${ }^{1, *}$, Darina Ondrušová ${ }^{1}$, Róbert Janík ${ }^{1}$, Zuzana Mičicová ${ }^{1}$, Beáta \\ Pecušová ${ }^{1}$, Ivan Labaj $^{1}$, Marcel Kohutiar ${ }^{1}$, and Katarina Moricová ${ }^{1}$ \\ ${ }^{1}$ Department of Materials Technologies and Environment, Faculty of Industrial Technologies in \\ Púchov, Alexander Dubček University of Trenčín, I. Krasku 491/30, 02001 Púchov, Slovak Republic
}

\begin{abstract}
The presented paper deals with a study of selected rubber compounds as well as their vulcanizates with partially replaced commonly used filler by adding selected alternative fillers. Alternative fillers were mixed into rubber compounds as partial replacement of commonly used filler - carbon black. As an alternative partial replacement of common filler, we have chosen fine fractions of the waste of thermoplastics. The differences of rubber compounds were based on the amount of used alternative filler. We determined vulcanization characteristics of prepared tread compounds and physical and mechanical properties and dynamic mechanical properties of their vulcanizates. From the measured results it can be concluded that studied waste can be used in the function of filler into rubber, as partial replacement of commonly used filler.
\end{abstract}

Keywords: polymeric materials, waste, thermoplastics, physical and mechanical properties, vulcanization characteristics, waste, dynamic mechanical properties

\section{Introduction}

The companies currently pay attention to the issue of how to utilise the resulting waste from polymeric materials in the most efficient way because this waste materials accumulates in the large quantities on the mainland as well as in the world's ocean. One of the ways, by which such waste can be used, is to be applied as material in production of new product, for example in the function of fillers in the elastomeric matrix [1,2]. Fillers, added to the rubber matrix, have a major influence on the physical-mechanical properties of vulcanizates, such as hardness, tensile strength, tensibility and moreover, they can also affect vulcanization characteristics, processing properties, or they can even act as accessory processing agents. Fillers are the most important additives in the rubber compound that alter its properties. They are mostly solids which contain very small particles that are well dispersible in rubber. They play a decisive role in processing of the rubber and thus improving the physical-mechanical properties of the resultant vulcanizates. The extent of the stiffening depends not only on particle size filler but also on the structure and the action of its surface [3-5].

\footnotetext{
* Corresponding author: mariana.pajtasova@fpt.tnuni.sk

Reviewers: Konrad Waluś, Milan Žmindák
} 


\section{Material and methods}

\subsection{Material}

The waste materials, namely polypropylene (PP), polylactide (PLA) and dried coffee grounds $(\mathrm{K})$, were used as partial substitution fillers in rubber compounds instead of predetermined amount of commonly used active filler - carbon black (N339). All these fillers were in powdery particle size up to $0.04 \mathrm{~mm}$.

\subsection{Preparation of rubber compounds}

The real rubber compound (standard ST) and its modified forms (PP, PLA a K) were prepared by two-step mixing in a closed Plastograph ${ }^{\circledR}$ EC Brabender laboratory mixer with chamber volume of $70 \mathrm{~cm}^{3}$ and $50 \mathrm{rpm}$ according to standards [6]. The first step of mixing was carried out at the temperature $120^{\circ} \mathrm{C}$ and the fillers (carbon black, PP, PLA and $\mathrm{K}$ ) were used. In the second step which was carried out at the temperature $100^{\circ} \mathrm{C}$ sulphur in function of vulcanization agent and accelerator of vulcanization were added [7, 8]. The selected fillers based on thermoplastic waste (PP, PLA) and coffee grounds (K) were used as partial replacement of the high reinforcing filler - carbon black of N339 type. The amount of used fillers in prepared rubber compounds is shown in Table 1.

Table 1. The amount of fillers in rubber compounds

\begin{tabular}{|c|c|c|}
\hline Compounds & Filler - carbon black N339 (phr) & Alternative fillers (phr) \\
\hline ST & 87 & 0 \\
\hline PP & 77 & 10 \\
\hline PLA & 77 & 10 \\
\hline K & 77 & 10 \\
\hline
\end{tabular}

After the first and second steps, the prepared rubber blends were homogenized, using the laboratory LaboWalz W80T double drum. The roller rotation speed was set at $20 \mathrm{rpm}$.

After the stirring process, the prepared blends were investigated from the aspect of the curing characteristics, using the Monsanto 100 Vulcameter. The given testing process was based on standardized procedures at temperature of $150^{\circ} \mathrm{C}$ and the recording of time for curing curves was 60 minutes according to standards.

Tensile properties were measured by Shimadzu Autograph AG-X universal testing machine at a laboratory temperature of $25^{\circ} \mathrm{C}$ and the test rate was set to $100 \mathrm{~mm} / \mathrm{min}$.

Hardness of prepared vulcanizates was measured by IRHD hardness tester with hardness ranging from 30 to $85 \mathrm{IRHD}$ at temperature $23 \pm 2^{\circ} \mathrm{C}$ and $6 \mathrm{~mm}$ test samples thickness.

Dynamic mechanical analysis (DMA) was performed by DMA Q800 thermal analysis device Q800 from the manufacturer TA Instruments. Experimental conditions have been set as follows: temperature from $75^{\circ} \mathrm{C}$ to $75^{\circ} \mathrm{C}$, heating rate of $3^{\circ} \mathrm{C} / \mathrm{min}$, frequency $1 \mathrm{~Hz}$. The data obtained from the measurements were processed in TA Universal Analysis 2000 software.

All measurements were carried out at the CEDITEK (Center for quality testing and diagnostics of materials) laboratories at Faculty of Industrial Technologies in Púchov. 


\section{Results and discussion}

\subsection{Study of rheology and vulcanization characteristics of rubber compounds}

The influence of the type of filler used on the sulphur vulcanization of the prepared rubber compounds was evaluated based on selected parameters of the vulcanization characteristics from the rheological records of their vulcanization curves. The following vulcanization characteristics were evaluated: minimum torque $\left(M_{L}\right)$, maximum torque $\left(M_{H}\right)$, processing safety of compound $\left(t_{s}\right)$, optimum time of vulcanization $\left(t_{c(90)}\right)$ and rate coefficient of vulcanization $\left(R_{v}\right)$. The values of the basic parameters of vulcanization characteristics of individual rubber blends containing PP, PLA or K comparable to the reference sample are shown in Table 2. Their graphical representation is shown in Fig. 1-3.

Table 2. Vulcanization characteristics of rubber compounds

\begin{tabular}{|c|c|c|c|c|c|c|}
\hline Compounds & $\boldsymbol{M}_{\boldsymbol{L}} \mathbf{( d N m )}$ & $\boldsymbol{M}_{\boldsymbol{H}}(\mathbf{d N m})$ & $\boldsymbol{\Delta M} \mathbf{( d N m )}$ & $\boldsymbol{t}_{\boldsymbol{s}}(\mathbf{m i n})$ & $\boldsymbol{t}_{\boldsymbol{c} \boldsymbol{9} \boldsymbol{\theta}}(\mathbf{m i n})$ & $\boldsymbol{R}_{\boldsymbol{v}}\left(\mathbf{m i n}^{-\mathbf{1}}\right)$ \\
\hline ST & 1.96 & 11.00 & 9.04 & 4.44 & 10.79 & 15.75 \\
\hline PP & 1.67 & 9.99 & 8.32 & 4.65 & 11.33 & 13.62 \\
\hline PLA & 1.61 & 9.50 & 7.89 & 4.87 & 27.84 & 4.35 \\
\hline K & 1.61 & 9.50 & 7.89 & 4.33 & 11.36 & 14.22 \\
\hline
\end{tabular}

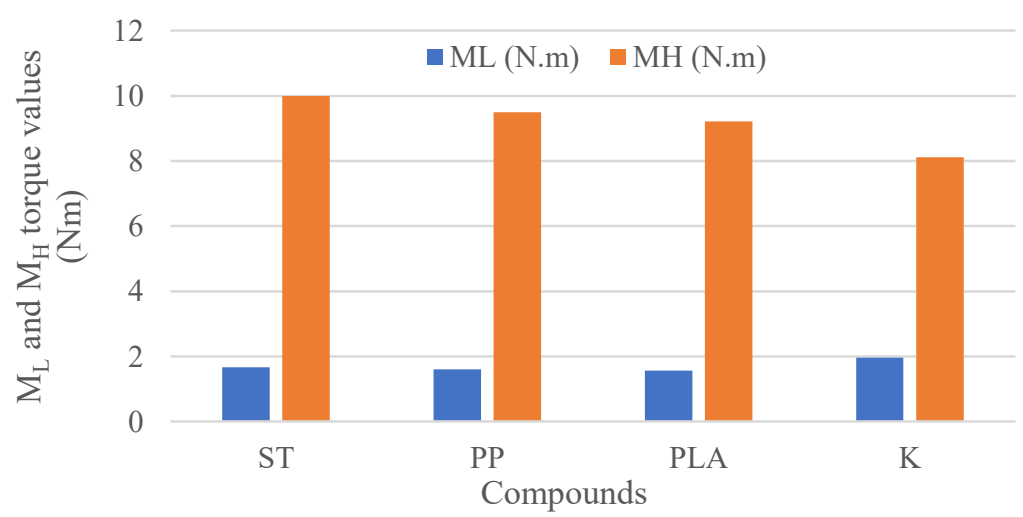

Fig. 1. Minimum torque ML and maximum torque MH of rubber compounds

From the measured results, the values of the minimum torque $\left(M_{L}\right)$ and the maximum torque values $\left(M_{H}\right)$ (Table 2, Fig. 1) of the prepared rubber blends with the content of the PP, PLA or K alternatives are lower at $10 \mathrm{phr}$ compared with the $M_{L}$ and $M_{H}$ values of the reference sample (ST). Compared with the $M_{H}$ reference value of ST, the lower values of the maximum torque $\left(M_{H}\right)$ for the prepared blends containing PP, PLA and K may be associated with lower stiffness and viscosity at the end of the vulcanization. 


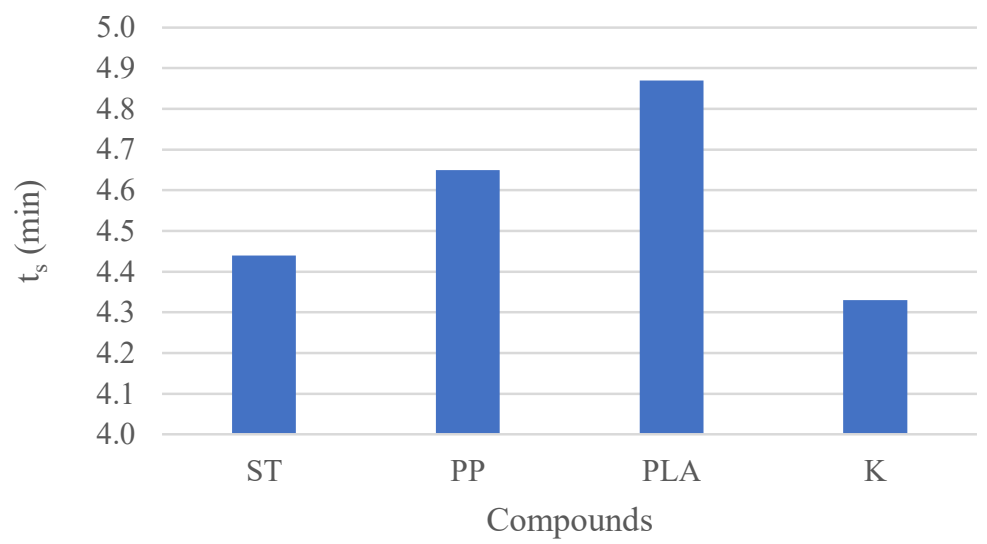

Fig. 2. Processing safety of compound

The values of processing safety $\left(t_{s}\right)$ for all blends with alternative fillers (Table 2, Fig. 2) are comparable with the $t_{s}$ of the ST reference compound.

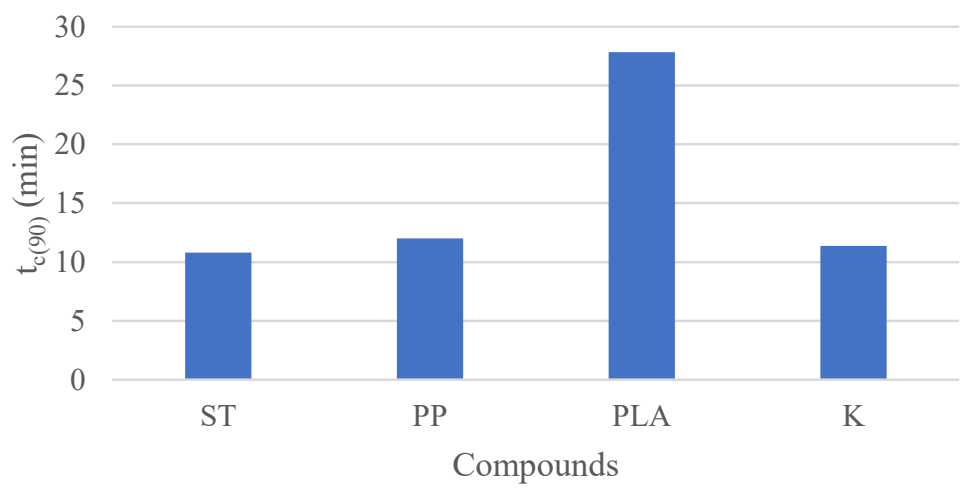

Fig. 3. Optimum time of vulcanization

In relation to the evaluation of optimum time of vulcanization $\left(t_{c(90)}\right)$ (Table 2, Fig. 3), it can be stated that the compositions with containing PP and $\mathrm{K}$ had slightly higher values of $t_{c(90)}$ compared with the ST reference sample. In the case of compound with a content of PLA filler, $t_{c(90)}$ was significantly higher than the reference sample ST. Extending the optimum vulcanization time may be useful for application in relation to the thick-walled rubber products, where the vulcanization process has to be slower [9]. 


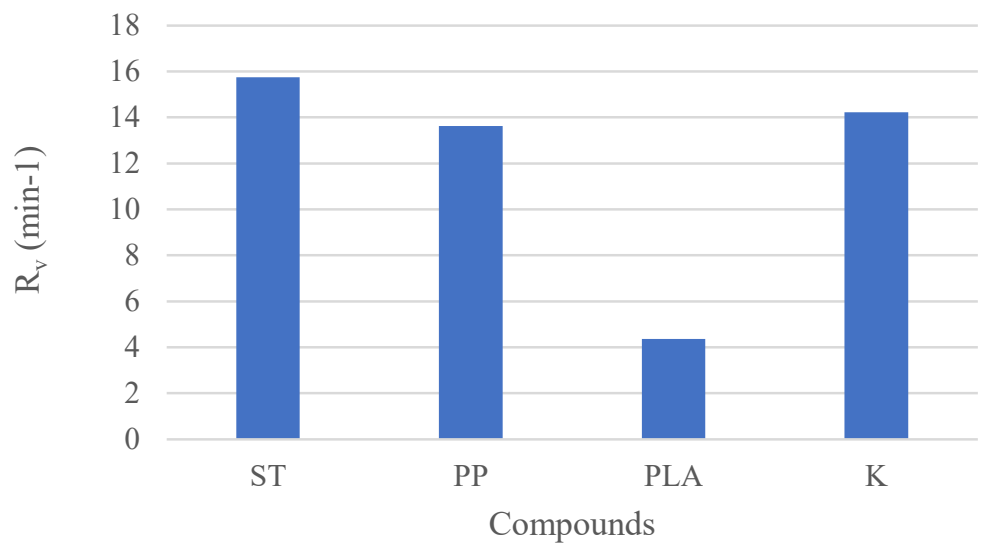

Fig. 4. Rate coefficient of vulcanization

All prepared rubber blends containing alternative fillers have a lower value of the coefficient of vulcanization rate $(R v)$ (Table 2, Fig. 4) compared with the ST reference sample. The lowest values of rate coefficient of vulcanization $(R v)$ compared with the ST reference sample, were reached in the case of rubber compound containing PLA filler and it may be, related to the lower activity of the components of the rubber compounds.

\subsection{Study of physical and mechanical properties of prepared vulcanizates}

The influence of the type of the selected alternative filler on the physical and mechanical properties such as tensile strength, tensibility and hardness was evaluated for the prepared vulcanizates. All prepared vulcanizates were compared with the reference sample of vulcanizate (ST). The results of the physical and mechanical properties are shown in graphical form in Figs. 5-7.

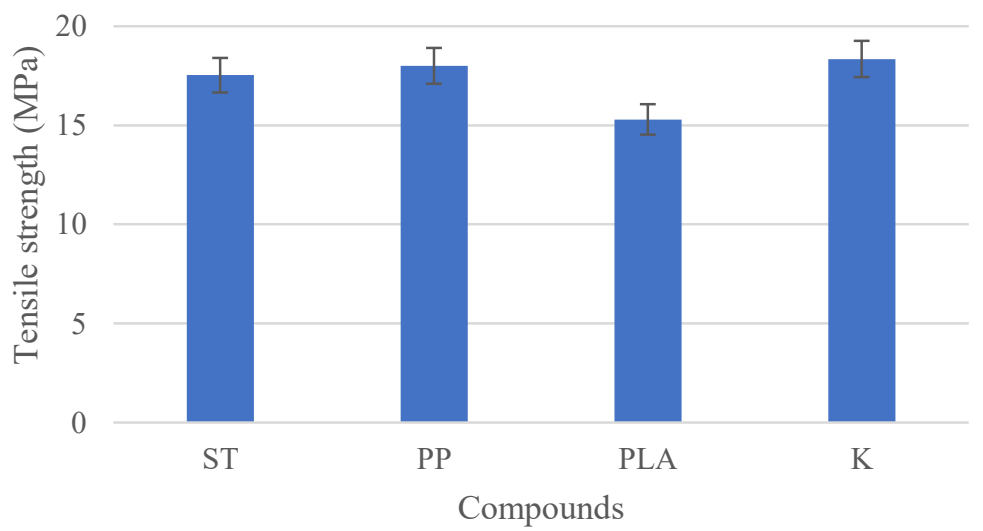

Fig. 5. Tensile strength of vulcanizates

The values of the tensile strength of the prepared vulcanizates with the content of PP and $\mathrm{K}$ alternative fillers were comparable, respectively. They are slightly increased compared to the reference sample of vulcanizate (ST). Increasing the values of tensile strength is probably 
associated with a more homogeneous structure. For vulcanizates with content of PLA filler, the values of tensile strength were slightly reduced, compared with the reference sample of vulcanizate (ST) (Fig. 5).

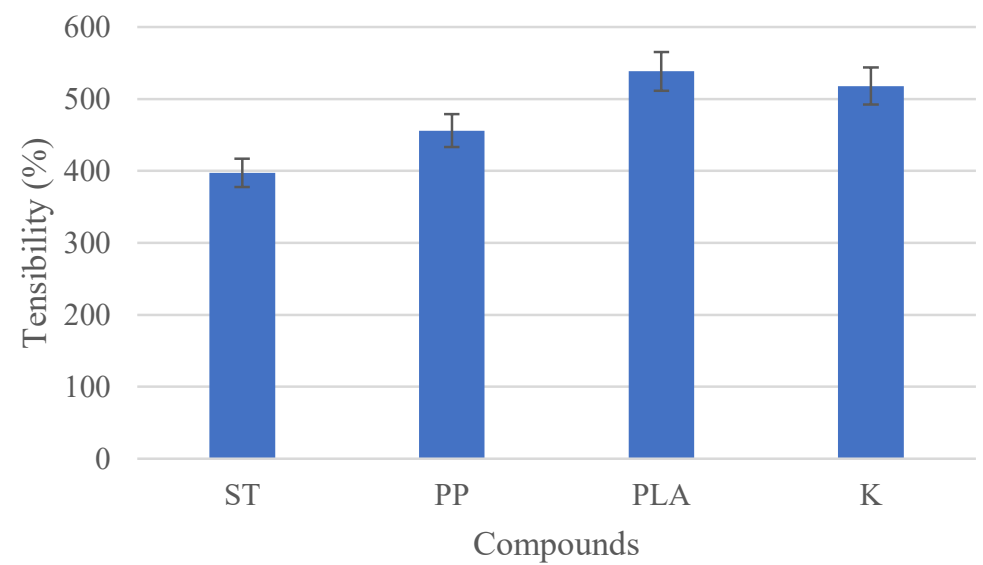

Fig. 6. Tensibility of vulcanizates

In the case of evaluation of the resulting tensibility (Fig. 6), it is observed that all of the prepared vulcanizates exhibit higher values compared to the reference vulcanizate (ST), and it leads to indication of a higher elasticity.

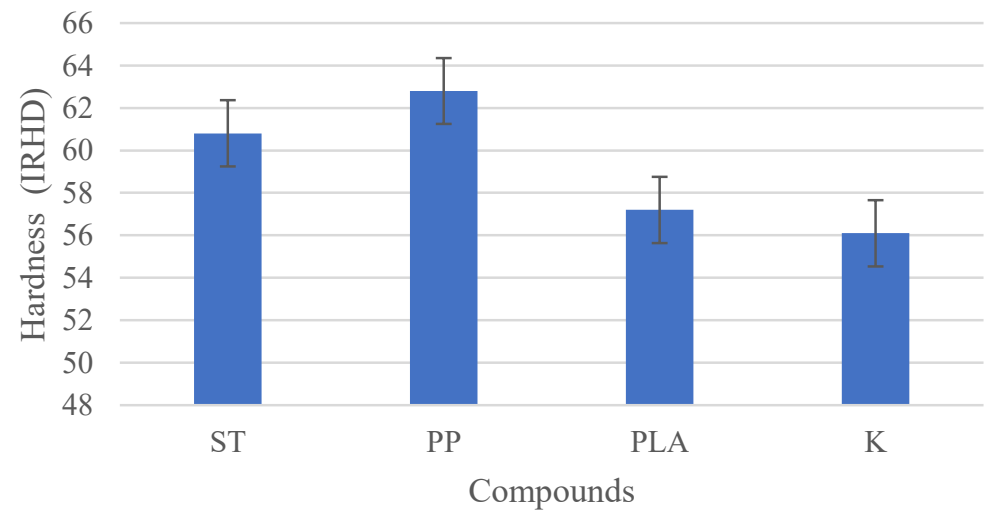

Fig. 7. Hardness of vulcanizates

The values of hardness (Fig. 7) for vulcanizates containing PLA and K filler were lower in comparison with the ST reference sample and the hardness values for vulcanizate containing PP filler showed comparable values with the reference vulcanizate (ST).

\subsection{Dynamical and mechanical analysis}

The viscoelastic behaviour of the prepared rubber vulcanizates with PP, PLA, K and reference vulcanizate (ST) was evaluated on the basis of the results of the dynamic mechanical analysis measurements in the temperature range from $-80^{\circ} \mathrm{C}$ to $+80^{\circ} \mathrm{C}$. The 
dependence of the dynamic mechanical properties - the storage modulus and the loss modulus, the loss angle $(\tan \delta)$ on the temperature is graphically depicted in Figs. 8-10.

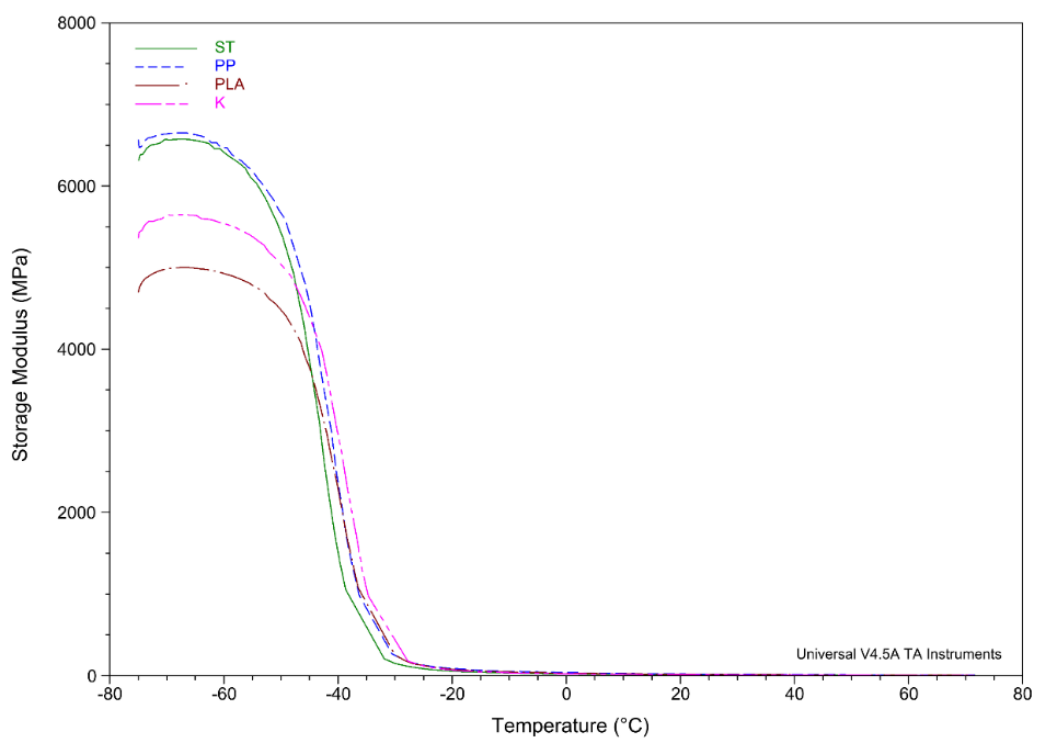

Fig. 8. Storage modulus of vulcanizates

As it is shown in Fig. 8, the PLA and $\mathrm{K}$ vulcanizate exhibit a decrease of the storage modulus in comparison with the standard vulcanizate and it ca be expressed in the following order: PLA $<\mathrm{K}$. The vulcanizate with PP filler has similar values to the reference vulcanizate (ST). These differences of the storage modulus are probably related to the different degree of interaction and dispersion between the waste material (PLA, PP or K) and the polymer matrix, where the lower storage modulus of the investigated vulcanizates exhibits better interaction at the interfacial interface and the filler dispersion $[10,11]$.

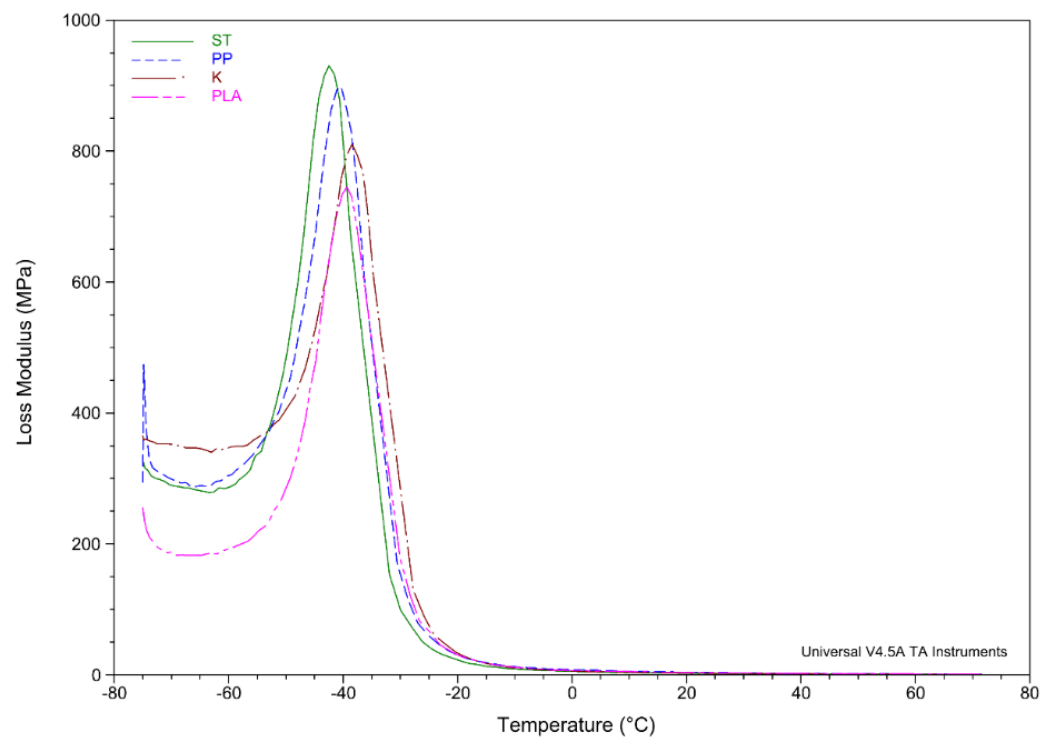

Fig. 9. Loss modulus of vulcanizates 
A similar trend can be observed in the loss modulus of the prepared vulcanizates. The trend is in the following order: PLA $<\mathrm{K}<\mathrm{PP}<\mathrm{ST}$ (Fig. 9).

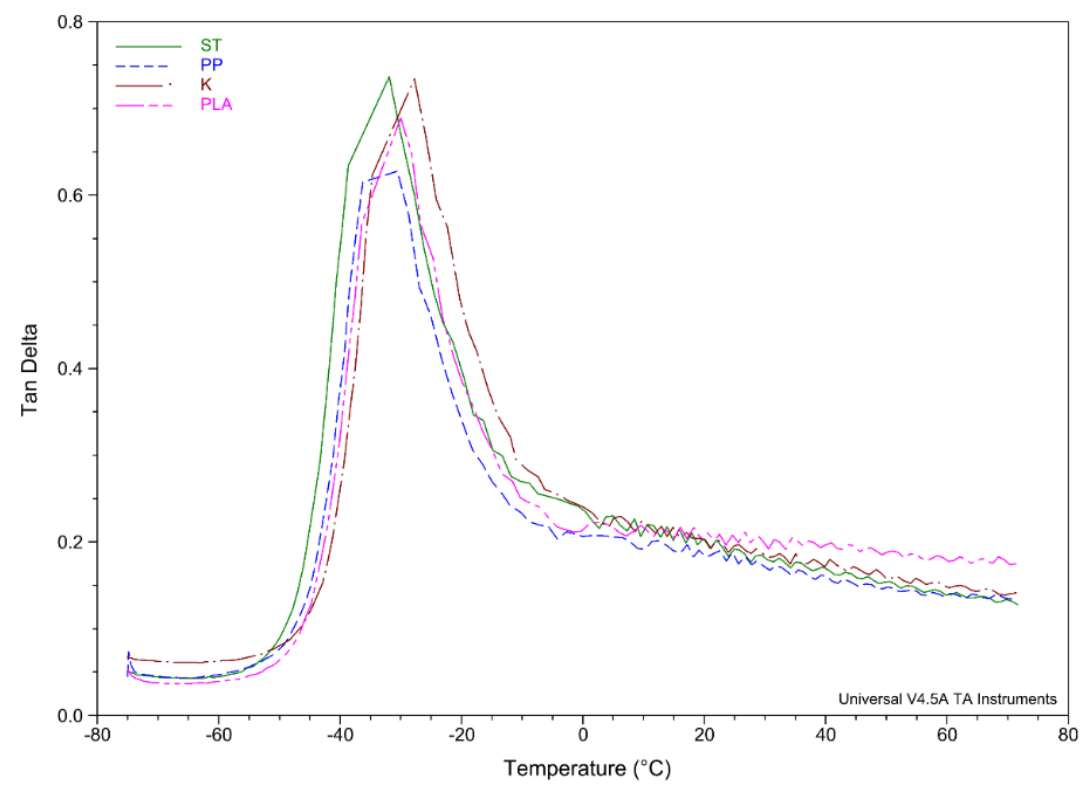

Fig. 10. Loss angle of vulcanizates

The glass transition temperatures of the prepared rubber vulcanizates is determined from the maximum peaks of the loss angle (tan $\delta$ ) (Fig. 10). Their values are shown in Table 3.

Table 3. The values for selected DMA parameters

\begin{tabular}{|c|c|c|c|c|c|}
\hline Compounds & $\boldsymbol{T g}\left({ }^{\circ} \mathbf{C}\right)$ & $\tan \boldsymbol{\delta}_{\max }$ & $\tan \boldsymbol{\delta}\left(-20^{\circ} \mathbf{C}\right)$ & $\tan \boldsymbol{\delta}\left(\mathbf{0}^{\circ} \mathbf{C}\right)$ & $\tan \boldsymbol{\delta}\left(\mathbf{6 0}^{\circ} \mathbf{C}\right)$ \\
\hline ST & -31.9 & 0.74 & 0.40 & 0.24 & 0.14 \\
\hline PP & -30.6 & 0.63 & 0.34 & 0.21 & 0.14 \\
\hline PLA & -30.0 & 0.73 & 0.39 & 0.21 & 0.18 \\
\hline K & -27.7 & 0.75 & 0.47 & 0.24 & 0.15 \\
\hline
\end{tabular}

The stiffening effect of the filler can be determined from the max. peak of $\tan \delta$. It is fact that the lower value of max. peak of $\tan \delta$, the better the stiffening effect of filling in the material. This is due to the limited mobility of the rubber molecule segments as a result of the stronger interaction between the matrix and the particle products between the phase interface [12]. Values of max. peak of $\tan \delta$ decrease for vulcanizates in the following order: $\mathrm{PP}<\mathrm{PLA}<\mathrm{ST}<\mathrm{K}$. The best stiffening effect can be observed for the PP filler and then for the PLA filler.

Based on the dependency of loss angle ( $\tan \delta$ ) on temperature, the selected properties for tyre tread vulcanizates were evaluated, including traction on snow and ice $\left(\tan \delta\left(-20^{\circ} \mathrm{C}\right)\right)$, traction on the wet surface $\left(\tan \delta\left(0^{\circ} \mathrm{C}\right)\right)$ and rolling resistance $\left(\tan \delta\left(60^{\circ} \mathrm{C}\right)\right)$ [13].

$\operatorname{Tan} \delta$ for $-20^{\circ} \mathrm{C}$ represents the traction on snow and ice. The $\mathrm{K}$ vulcanizate exhibits best traction on snow and ice in comparison with ST, PP and PLA vulcanizates. Tan $\delta$ for $0^{\circ} \mathrm{C}$ represents traction on the wet surface. The ST and K vulcanizates exhibit the best traction on the wet surface. Tan $\delta$ for $60^{\circ} \mathrm{C}$ represents the rolling resistance. The ST and PP vulcanizates exhibit the best rolling resistance in comparison with PLA and K vulcanizates. 


\section{Conclusion}

The paper deals with the application of waste polypropylene and polylactide waste in powder form and coffee grounds which were implemented to the selected tyre tread rubber compound. We determined vulcanization characteristics of prepared tread compounds and physical and mechanical properties and dynamic mechanical properties of their vulcanizates. The vulcanization characteristics as minimum torque, maximum torque, processing safety of compound, optimum time of vulcanization and rate coefficient of vulcanization, were evaluated. The influence of the type of the selected alternative filler on the physical and mechanical properties such as tensile strength, tensibility and hardness was evaluated for the prepared vulcanizates. The viscoelastic behaviour of the prepared rubber vulcanizates with alternative fillers and reference vulcanizate was evaluated on the basis of the results of the dynamic mechanical analysis measurements (the storage modulus and the loss modulus and the loss angle).

On the basis of the results obtained it can be conclude that the standard or common carbon black filler (N339) can be replaced partially with waste from selected thermoplastics and coffee grounds. The presented results provide or give new insights into the use of thermoplastic waste and coffee grounds in rubber blends.

This work was supported by the Slovak Grant Agency VEGA 1/0589/17, VEGA 1/0649/17 KEGA 007 TnUAD-4/2017 and resulted from the project "Center for quality testing and diagnostics of materials", ITMS code 26210120046 relating to the Operational Program Research and Development funded from European Fund of Regional Development.

\section{References}

1. K. Holcová, M. Pajtášová, L. Špániková, J. Paliesková, Z. Jankurová, M. Janeková, Study of the properties for rubber compounds with fillers based on PLA and PP Fibers. Hutnické listy 3. - ISSN 0018-8069, s. 106-109 (2014)

2. P. Boral, T. Nieszporek, Analiza geometryczna ukladu uplastyczniającego wyttaczarki złożonego z dwóch ślimaków stożkowych-Geometric Analysis of Plasticizing System in the Extruder Consisting of Two Cone Worms, Polimery 7-8, ISSN 0032-2725, s.571-576 (2012)

3. Z. Mičicová, M. Pajtášová, S. Domčeková, D. Ondrušová, L. Raník, T. Liptáková, Inorganic materials and their use in polymeric materials. Procedia Engineering 136, 239-244 (2016)

4. V. Ducháček, Gumárenské suroviny a jejich zpracování. Praha: VŠCHT, ISBN 97880-7080-713-2, s. 199 (1999)

5. J. MALÁČ, J. Gumárenská technológie. Zlín: Univerzita Tomáše Bati ve Zlíně, s.156 (2005)

6. STN 62 1425: Raw rubber. A preparation of rubber compounds, 1984 (in Slovak)

7. D. Ondrušová, M. Pajtášová, Rubber components and their influence on rubber properties and environmental aspects of production. Krakow: Spolok Slovákov v Pol'sku, 2011. 166 s. ISBN 978-83-7490-358-1.

8. D. Ondrušová, S. Domčeková, M. Pajtášová, A. Dubec, Z. Mičicová, B. Pecušová, Alternative filler based on the waste from glass production and its effect on the rubber properties. Procedia Engineering 177, $462-469$ (2017) 
9. A.V. Chapman, A.J. Tinker, Vulcanization of Blends - Crosslink Distribution and its Effect on Properties. KGK-Kautschuk Gummi Kunstsoffe 56, 533-544 (2003)

10. M. Bhattacharya, A.K. Bhowmick, Synergy in carbon black-filled natural rubber nanocomposites. Part I: Mechanical, dynamic mechanical properties, and morphology. Journal of Materials Science 45, 6126-6138 (2010)

11. Pajtášová M, Z. Mičicová, D. Ondrušová, S. Božeková, R. Janík, B. Pecušová and L. Raník, Use of waste materials in rubber matrix. MATEC Web of Conferences 157, 07009 (2018)

12. A. Das, R. Jurk, K. Werner Stöckelhuber, G. Heinrich, Effect of Vulcanization Ingredients on the Intercalation-Exfoliation Process of Layered Silicate in an Acrylonitrile Butadiene Rubber Matrix. Macromolecular Materials and Engineering 293, 479-490 (2008)

13. A. Gantowski, P. Palutkiewicz, E. Boceąga, Numerical analysis of stress state during single point bending in DMTA examination. Journal of Achievements in Materials and Manufacturing Engineering 28, 47-50 (2008) 